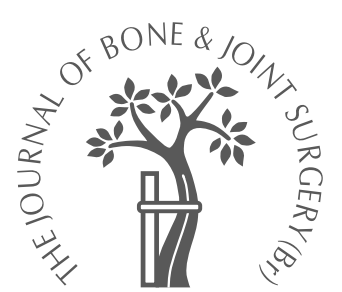

S. Kaspar, J. de V de Beer

From McMaster University, Hamilton, Canada

S. Kaspar, MD, MSc, FRCSC, Orthopaedic Spine Surgeon

Department of Orthopaedics, McFarland Clinic PC, 1215 Duff Avenue, Ames, lowa 50010, USA.

J. de $\mathrm{V}$ de Beer, MD FRCSC, Director, Hamilton Arthroplasty Group Henderson Hospital, 711 Concession Street, Hamilton, Ontario K8V 1C3, Canada.

Correspondence should be sent to Dr S. Kaspar; e-mail: mightysamster1@aol.com

(C)2005 British Editorial Society of Bone and Joint Surgery doi:10.1302/0301-620X.87B4. $15546 \$ 2.00$

$J$ Bone Joint Surg $[\mathrm{Br}]$ 2005;87-B:454-7.

Received 7 April 2004 Accepted after revision 25 May 2004

\title{
Infection in hip arthroplasty after previous injection of steroid
}

Immunosuppression following intra-articular injections of steroid into the hip may interfere with asepsis in a subsequent total hip arthroplasty (THA). We have undertaken a retrospective, matched, cohort study of infective complications after THA, in 40 patients who had received such an injection and $\mathbf{4 0}$ who had not.

In the injection group there were five revisions, four of which were for deep infection. There were none in the matched group. The overall rate of revision in our database of 979 primary THAs was $1.02 \%$. Six additional patients who had received injections underwent investigation for infection because of persistent problems in the hip as compared with one in the control group.

Intra-articular injection of steroid for the treatment of pain in adult osteoarthritis of the hip has been a recommended method of treatment for the past five decades. However, its efficacy is uncertain ${ }^{1-2}$ since it has repeatedly been shown to provide only modest improvement ${ }^{3-5}$ or negligible benefit. ${ }^{6-10}$ Non-invasive medical management of arthritis and the success of total hip arthroplasty (THA) ${ }^{11-14}$ has made its role less certain. The immunosuppressive nature of invasive steroid therapy may possibly influence the susceptibility to infection of any subsequent surgical procedure. Factors which could inhibit the ability of the hip to withstand an infectious inoculum at surgery should be minimised, especially in view of the reports of very high rates $(63 \%)$ of contamination in typical surgical fields during THA, although these bacteria rarely lead to frank infection. ${ }^{15}$ Infection could also be introduced at the time of an injection.

To our knowledge there has not been a study of the outcomes of THA in patients who had previously undergone intraarticular injection. We carried out an audit at a tertiary-care hospital to determine the influence of such a procedure on the rate of infection of subsequent operation carried out on the hip for osteoarthritis.

\section{Patients and Methods}

We undertook a retrospective, matched cohort study on two groups of patients, one of which had received intra-articular steroid while the second had not. By inspection of the records of the fluoroscopy suite, we obtained the details of all patients who had received such an injection between 1995 and 1998. There were 134 injections in 106 patients, including 76 in 66 patients who had not received a THA. These latter patients were not included in our study. The remaining 40 patients ( 25 men, 15 women) were matched with a comparable cohort from our THA database and both groups analysed. One further patient, who had received a THA after injection, was excluded because of prostatic malignancy which might have affected his hip. Other exclusion criteria included a previous ipsilateral fracture of the hip or earlier surgery on the affected side. A diagnosis of inflammatory arthritis was present in only one patient of the 40 in each group. These patients were not excluded and neither developed an infection. No patient was included who was immunocompromised, previously or presently infected, affected with cancer in the hip or suspected tumours around the hip or who had been given an initial diagnosis of avascular necrosis. The remaining 39 patients in the matched cohorts had an initial diagnosis of osteoarthritis.

The patients who had not received an injection were matched from our database in descending order of priority, by gender, cemented or cementless THA, age, body mass index (BMI), American Society of Anaesthesia (ASA) pre-operative score, the year of THA, and the surgeon. If exclusion criteria were encountered while gathering non-injected patients from the database, then the next 
Table I. Baseline details of the patients at the time of THA

\begin{tabular}{|c|c|c|c|c|c|c|c|}
\hline \multirow[b]{2}{*}{ Parameter } & \multicolumn{3}{|c|}{ Control group } & \multicolumn{4}{|c|}{ Injected group } \\
\hline & Mean \pm SEM & Range & Median & Mean \pm SEM & Range & Median & p value \\
\hline Age (yrs) & $70.55 \pm 1.50$ & 46 to 87 & 71 & $71.03 \pm 1.53$ & 45 to 87 & 71 & 0.82 \\
\hline BMI $\left(\mathrm{kg} / \mathrm{m}^{2}\right)$ & $29.94 \pm 0.77$ & 20.9 to 43 & 29.25 & $28.58 \pm 0.72$ & 17.4 to 39.3 & 27.85 & 0.20 \\
\hline Length of stay (days) & $7.26 \pm 0.96$ & 4 to 36 & 6 & $6.58 \pm 0.49$ & 2 to 18 & 6 & 0.52 \\
\hline
\end{tabular}

closest match was used. The database included patients who had undergone a THA by one of seven orthopaedic surgeons who subspecialised in arthroplasty.

The injections had been given for pain in nine patients, to distinguish from symptoms between the hip as opposed to the knee in two, to confirm that symptoms arose from the hip as opposed to the spine in 13, to delay THA for medical reasons in two or because osteoarthritis was mild in one. The remaining 13 patients received injections in order to alleviate their symptoms while they were awaiting arthroplasty.

Problems with the spine were common in both groups and were present in approximately half of the patients studied. Functional hip scores ${ }^{16,17}$ were also obtained for use in a future report.

The groups for comparison were formed retrospectively. By the end of the review the length of follow-up (mean \pm SEM) after the primary THA for the entire database was $29.8 \pm 0.4$ months $(7.4$ to 53.0, median 29.8). For those with a previous injection the follow-up was $33.2 \pm 2.1$ months (9.9 to 86.2, median 32.8) and for those without $30.2 \pm 1.6$ months ( 11.8 to 53.0 , median 27.4 ).

In order to ensure consistency, all data were gathered, and analysed by the first author (SK). This included a review of all available hospital records of blood chemistry, microbiology, bone scans, consultations, operative and clinic notes, and radiographs. A record was made of wound drainage or cultures, revision surgery, and any investigations for infection including bone scans, hip aspirations, the level of C-reactive protein and the ESR. The hospital records were available for all 80 patients.

All intra-articular injections had been performed in a fluoroscopy suite by radiologists wearing a mask and sterile gown, after sterile preparation of the patient's skin with povidone-iodine solution. Radiopaque contrast medium was injected through a 22-gauge spinal needle in order to confirm intra-articular placement, followed by injection of $80 \mathrm{mg}$ of methylprednisolone (Depo-Medrol; Pharmacia Upjohn), which was usually mixed with $1 \mathrm{ml}$ to $5 \mathrm{ml}$ of bupivacaine.

Graphs were drawn using the SPSS version 10.0 and Microsoft Excel 2000 and statistical analysis was conducted by SPSS software (SPSS Inc, Chicago, Illinois). Specific analytical tests included descriptive statistics, unpaired $t$-tests, Fisher's exact test when appropriate for categorical data with cell values less than or equal to five, KaplanMeier survival analysis, and comparison of survival plots by Mantel-Cox type log-rank testing. Power analysis was performed by univariate modelling unless otherwise specified. Confidence intervals (CI) for survivorship to revision were calculated from the SEM at the final Kaplan-Meier plateau of each plot and multiplied by the appropriate z-score for a $95 \%$ CI. A p value of less than 0.05 was considered to be significant.

\section{Results}

Baseline details. The baseline parameters of gender and the use of cemented implants (19) and non-cemented (21) were identical in the two groups. Similarly, age, BMI, and length of stay, showed no significant differences either qualitatively or statistically (Table I). The mean ASA score was 2.2 for both groups, indicating that most patients had few comorbidities.

Infectious complications. The rate of infection in the injected group was disturbing, with four cases of deep infection after THA. These contributed to an overall rate of revision of $12.5 \%$ (5 of 40 ) in this group compared with $1.02 \%$ (10 of 979) of failed primary THAs at our hospital over the same period. These latter figures exclude patients whose primary THA had been performed either elsewhere or at our hospital before the creation of the database. The injection group had significantly more infectious complications than the other group. Overall, the rate of established infection and/or tests querying possible infection, was 30\% (12 of 40 ) in the injected group compared with $7.5 \%$ (3 of 40 ) in those who had not received an injection. There were no deep infections in the latter group (Fisher's exact one-sided test, $\mathrm{p}=0.01)$. The deep infections in the injected group were caused by Streptococcus viridans, Staphylococcus aureus, Acinetobacter lwoffi, ${ }^{18}$ and a septic haematoma which was aspirated for purulent fluid in a patient on empirical antibiotics followed by surgical exploration.

Because the injected group was a sample of an entire cohort of such patients and the matched control group were only 40 of $1019(979+40)$ primary THAs carried out at our hospital, the high accuracy of the manual chart reviews in the two matched groups was obtained at the peril of potentially undersampling the database (40 of $1019=$ $3.9 \%$ ). Conversely, the database would not be expected to be as accurate as a manual review of the entire patient records, although the high numbers gave a better sampling of the overall pool. For these reasons, as well as the crosssectional nature of the periods of follow-up, the rate of revision was presented as a Kaplan-Meier survival function (Fig. 1) which provides a robust context for the findings. Comparing the three Kaplan-Meier plots, the log-rank sta- 


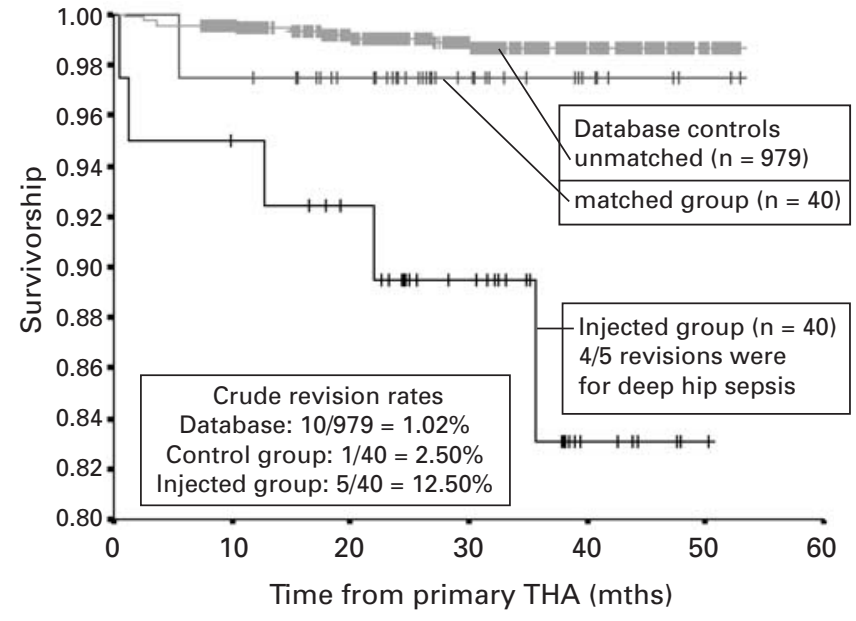

Fig. 1

Kaplan-Meier survivorship analysis, with failures being defined as revision hip surgery for any reason, including deep hip sepsis. The septic haematoma (case 24) was included as a revision in the injection group at 0.5 months, despite retention of the components since this is our practice for early infection of a well-seated THA..$^{23,24}$

tistic was 32.89 ( $\mathrm{p}<0.0001)$, with survivorship extrapolated out to 53 months as follows. In the whole database, the control and the injected groups, the mean $\pm 95 \%$ CIs for survivorship for 50 months were $0.987 \pm 0.004,0.975$ \pm 0.020 , and $0.831 \pm 0.064$, respectively, and the crude revision rates, without hazard analysis, were $1.02 \%$ (10 of 979), $2.5 \%$ (1 of 40 ) and $12.5 \%$ (5 of 40 ) respectively (Table II). Neither the total number of injections before THA nor the time interval between the injection and the operation differed between the groups (Table II). However, for the particular measures documented in Table II, our study was underpowered.

\section{Discussion}

This study has the inherent limitations of any retrospective review. However, the hip scores and follow-up visits were performed prospectively. The delineation into cohorts and the review of the records were undertaken by one individual retrospectively and separately from patient care. The outcome measures, such as infection and revision surgery, were selected because they were likely to be well documented in hospital records. Some selection bias may have been introduced since the choice of candidates for injec- tions was by multiple surgeons, rheumatologists and other practitioners. Personality, associated spinal problems or other factors, may bias a medical practitioner towards or against injection of the hip before surgery. However, there were clear radiological findings of osteoarthritis in all patients, except in one with mild disease, which suggests that such bias was minimal.

We initially anticipated that our study should be a pilot for a prospective assessment of the value of injection into the hip. However, when the high rate of subsequent infection after arthroplasty became apparent, a prospective study was judged to be both unnecessary and harmful. Reviews from other centres, or a multicentre retrospective review, would shed more light on these issues, since confounding problems at a single centre would theoretically be reduced by multicentre participation. It would also allow further statistical power, even if multiple sub-groups were to be analysed. While there were no demonstrable deep infections occurring immediately after injection, the study does show clear findings of both subjective and objective problems following subsequent arthroplasty.

In the 1995 guidelines of the American College of Rheumatology (ACR), injection with steroid was discussed as an option in the management of osteoarthritis in both the hip and the knee. It was noted then that its efficacy in patients with osteoarthritis of the hip had not been studied. Further comment was made that multiple injections into joints may cause progressive damage to the articular cartilage. ${ }^{19}$ In subsequent correspondence, it was noted that the benefits of an injection into the hip were often short-lived and raised the question as to whether the procedure was worthwhile. ${ }^{2}$ Creamer's review ${ }^{20}$ emphasised that there was limited evidence either for or against injection, and that much of the relevant literature concerned experimental work in which the response may be different. ${ }^{21}$ More recent updates to the 1995 ACR guidelines ${ }^{22}$ summarised newer information in multiple areas of the treatment of osteoarthritis. However, these guidelines addressed osteoarthritis of the knee treated by viscosupplementation or injection of steroid, not the hip.

Findings such as ours may not have been recorded previously since the number of patients undergoing THA who have previously had a steroid injection into the joint is small, being about $4 \%$ of the database in our study. An injection may have been made before referral for surgery which may lessen the possibility of establishing a link

Table II. Time interval between injection and THA for the groups with and without infection complications or tests. In the uninfected group there were 28 patients after the exclusion of one outlier with 11.4 years between injection of steroid and THA

\begin{tabular}{|c|c|c|c|c|c|c|c|c|}
\hline & \multicolumn{3}{|c|}{ Infection and/or infections tests } & \multicolumn{3}{|c|}{ No infection and no infection tests } & \multirow[b]{2}{*}{ p value } & \multirow[b]{2}{*}{ Power } \\
\hline & $\begin{array}{l}\text { Mean } \pm \text { SEM } \\
95 \% \mathrm{CI}\end{array}$ & Range & Median & $\begin{array}{l}\text { Mean } \pm \text { SEM } \\
95 \% \mathrm{CI}\end{array}$ & Range & Median & & \\
\hline Time between most recent injection and THA & $\begin{array}{c}11.38 \pm 3.03 \\
5.6 \text { to } 17.2\end{array}$ & $\begin{array}{l}0.5 \text { to } \\
29.0\end{array}$ & 6.97 & $\begin{array}{c}10.86 \pm 1.74 \\
7.2 \text { to } 14.5\end{array}$ & 1.7 to 42.9 & 8.52 & 0.878 & 0.053 \\
\hline Total number of injections before THA & $1.43 \pm 0.25$ & & & $1.46 \pm 0.11$ & & & 0.891 & 0.052 \\
\hline
\end{tabular}


between the injection and an infected THA. However, our data do highlight significant problems with THA after steroid injection. Despite the moderate size of our study the complications in the injection group were exceptional with $30 \%$ having some form of sepsis or work up for sepsis of the hip, a rate which was four times higher than that of the control group. Established deep infection which required revision occurred in $10 \%$ of the injection group compared with none in the group not receiving an injection. The overall rate of revision for the injection group was $12.5 \%$ compared with $1.02 \%$ of 979 THAs carried out at our hospital during the same period.

We do not know which component of the injection procedure may be culpable, be it the arthrography dye, the steroid itself or its depot vehicle, contamination of the local anaesthetic, the invasiveness of a needle through prepared skin, or any breech of sterile technique by the radiologist. However, the records which we reviewed and discussions with the radiology department, suggest strong attention to aseptic technique by the interventional radiologists.

There is currently no evidence as to the value of injection of steroid in osteoarthritis of the hip. The potential dangers indicated by our study suggest that in patients who are likely to be candidates for THA the injection of intra-articular steroid into the hip is contraindicated.

\section{Supplementary material}

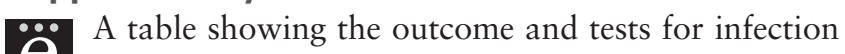
in the injected and control groups post-operatively is available with the electronic version of this article on our website at www.jbjs.org.uk

We thank Dr Coleman Rotstein, Consultant in Infectious Disease, for his review of the microbiological aspects of the final manuscript. The invaluable assistance of Danielle Petruccelli and Chrystal Church from the Research Office a the Hamilton Arthroplasty Group is gratefully acknowledged, particularly for maintaining the patient database. This project was funded through a grant to $S$. Kaspar (Primary Investigator) with Justin de V de Beer (Primary Supervisor) from the Physicians' Services Incorporated Foundation of Ontario (PSI).

No benefits in any form have been received or will be received from a commercial party related directly or indirectly to the subject of this article.

\section{References}

1. Swezey RL. Comment on the American College of Rheumatology guidelines for osteoarthritis of the knee and hip. Arthritis Rheum 1996;39:2083.

2. Neustadt DH. Local steroid injections: comment on the American College of Rheumatology guidelines for the management of osteoarthritis of the hip and on the letter by Swezey. Arthritis Rheum 1997;40:1914-15.
3. Hollander JL, Brown EM, Jessar RA, Brown CY. Hydrocortisone and cortisone injected into arthritic joints: comparative effects of and use of hydrocortisone as a local antiarthritic agent. JAMA 1951;147:1629-35.

4. Hollander JL. Intra-articular hydrocortisone in arthritis and allied conditions: a summary of two years' clinical experience. J Bone Joint Surg [Am] 1953;35-A:983-90.

5. Leveaux VM, Quinn CE. Local injections of hydrocortisone and procaine in osteoarthritis of the hip. Ann Rheum Dis 1956;15:330-6.

6. Flanagan J, Thomas TL, Casale FF, Desai KB. Intra-articular injection for pain relief in patients awaiting hip replacement. Ann R Coll Surg Eng/ 1988;70:156-7.

7. Smith RW, Cook PL, Cawley MD. A survey of arthrography and intra-articular corticosteroid injection of the hip joint [abstract]. Br J Rheumatol 1994;33(Suppl 1):76.

8. Plant MJ, Borg AA, Dziedzic K, Dawes PT. Intra-articular steroid injection of the hip improves pain and movement at two weeks but not at three months [abstract]. $\mathrm{Br}$ J Rheumato/ 1994;33(Suppl 1):76.

9. Griffith SM, Dziedzik K, Cheung NT, Dean T, Jones PW, Dawes PT. Clinical outcomes: a double-blind randomized controlled trial to compare the effect of intra-articular local anaesthetic and local anaesthetic plus steroid in hip arthritis [abstract]. $\mathrm{Br}$ J Rheumatol 1997;36(Suppl 1):21.

10. Plant MJ, Borg AA, Dziedzic K, Saklatvala J, Dawes PT. Radiographic patterns and response to corticosteroid hip injection. Ann Rheum Dis 1997;56:476-80.

11. Rasquinha VJ, Ranawat CS. Durability of the cemented femoral stem in patients 60 to 80 years old. Clin Orthop 2004;419:115-23.

12. Engh CA Jr, Culpepper WJ 2nd, Engh CA. Long-term results of use of the anatomic medullary locking prosthesis in total hip arthroplasty. J Bone Joint Surg [Am] 1997;79-A:177-84

13. Urban KA, Garvin KL, Boese CK, et al. Ceramic-on-polyethylene bearing surfaces in total hip arthroplasty: seventeen to twenty-one-year results. J Bone Joint Surg [Am] 2001;83-A:1688-94.

14. Berry DR, Harmsen WS, Cabanela ME, Morrey BF. Twenty-five year survivorship of two thousand consecutive primary Charnley total hip replacements: factors affecting survivorship of acetabular and femoral components. J Bone Joint Surg [Am]2002; 84-A:171-7.

15. Davis N, Curry A, Gambhir AK, et al. Intraoperative bacterial contamination in operations for joint replacement. J Bone Joint Surg [Br] 1999;81-B:886-9.

16. Harris WH. Traumatic arthritis of the hip after dislocation and acetabular fractures: treatment by mold arthroplasty: an end-result study using a new method of result evaluation. J Bone Joint Surg [Am] 1969;51-A:737-55.

17. Dawson J, Fitzpatrick R, Carr A, Murray D. Questionnaire on the perceptions of patients about total hip replacement. J Bone Joint Surg [Br] 1996;78-B:185-90.

18. Allen DM, Hartman BJ. Acinetobacter species. In: Mandell GL, Bennett JE, Dolin $R$ eds. Mandell, Douglas, and Bennett's principles and practice of infectious diseases. Fifth ed. Philadelphia: Churchill Livingstone, 2000:2339-44.

19. Hochberg MC, Altman RD, Brandt KD, et al. Guidelines for the medical management of osteoarthritis: part I osteoarthritis of the hip. Arthritis Rheum 1995;38: $1535-40$.

20. Creamer P. Intra-articular corticosteroid treatment in osteoarthritis. Curr Opin Rheumato/ 1999;11:417-21.

21. Gray RG, Gottlieb NL. Intra-articular corticosteroids: an updated assessment. Clin Orthop 1983;177:235-63.

22. American College of Rheumatology Subcommittee on Osteoarthritis Guidelines. Recommendations for the medical management of osteoarthritis of the hip and knee. Arthritis Rheum 2000;43:1905-15.

23. Crockarell JR, Hanssen AD, Osmon DR, Morrey BF. Treatment of infection with debridement and retention of the components following hip arthroplasty. J Bone Joint Surg [Am] 1998;80-A:1306-13.

24. Salvati EA, Gonzalez Della Valle A, Masri BA, Duncan CP. The infected total hip arthroplasty. Instr Course Lect 2003;52:223-45. 